\title{
The Optimal Babel \\ An Economic Framework for the Analysis of Dynamic Language Rights
}

Bengt-Arne Wickström

CESIFO WORKING PAPER NO. 2956

CATEGory 1: Public FinANCE

FEBRUARY 2010

An electronic version of the paper may be downloaded

- from the SSRN website:

- from the RePEc website:

- from the CESifo website:

www.SSRN.com

www.RePEc.org

www.CESifo-group.org/wp 


\title{
The Optimal Babel An Economic Framework for the Analysis of Dynamic Language Rights
}

\begin{abstract}
We analyze various normatively determined distributions of language rights in multilingual settings. A general model for the analysis of language rights over time in a model with overlapping generations is set up. This model is then first used to find efficient allocations of rights in the tradition of Wicksell. It is shown that, when rights today influence the status of a language in the future, the "naïve" static analysis has to be augmented in favor of furtherreaching minority rights in order to take into account the dynamic aspect. It is then demonstrated that a traditional welfare-economic analysis generally goes even further in the support of minority rights. If a possible externality on other communities is taken into account, however, these results are reversed in a pure efficiency analysis. If redistribution arguments are taken into account, this provides an effect in the opposite direction again.
\end{abstract}

JEL-Code: D61, D62, D63, D69.

Keywords: equivalence principle, minority rights, changeable preferences, dynamic preferences, welfare economics, overlapping generations.

\author{
Bengt-Arne Wickström \\ Faculty of Economics and Business Administration \\ Humboldt University Berlin \\ Spandauer Strasse 1 \\ 10178 Berlin \\ Germany \\ wickstr@wiwi.hu-berlin.de
}

February 10, 2010

This essay was begun during a visit to Dipartimento di Economia Pubblica, Facoltà di Economia, Università di Roma "La Sapienza". I would like to thank my hosts, especially Maria and Giuseppe Eusepi, for excellent and inspiring working conditions and a very pleasant stay. 


\section{Introduction}

Language is certainly the most important means of communication in all human societies. At the same time, language is one of the most important aspects of an individual's personality, as well as of its social and cultural identity. These two aspects of language often find themselves in conflict with one another. On the one hand, network externality properties of the communication aspect implies that the greater is the number of speakers of a certain language, the more useful is that language in communication and in the limit it would be efficient to have only one single language for communication purposes.

Balancing this tendency is the desire of many individuals to preserve their language as a marker of identity. In a static perspective, language, like talents and other personal characteristics, can be seen as part of the definition, or initial endowment, of the individual. In a dynamic setting, however, the situation is slightly more complex. Firstly, we have to distinguish between dynamics within a generation and between generations. Of course, an individual can over its lifespan change its language, or acquire additional idioms. However, the more drastic changes occur between generations, where a language shift often happens over three consecutive generations: the members of one generation are unilingual in one language, their children grow up bilingual and their grandchildren unilingual in the second language.

The survival of a language, its implantation in the next generation, depends on many factors, one of which is the status of the language in society. This status is influenced by, among other things, the possibilities to use the language in various social areas, domains.

Whether a language receives an official status in any specific domain or not, is very often a political issue, and it is an instrument that can be used by those in power - be it a dominant majority or a political elite - to control and exploit those who are weak, whether they are underprivileged masses or ethnic minorities or both. An analysis of these aspects is closely related to rent-seeking and political, social and economic power. These are questions analyzed in positive economics.

One can also, however, look at the problem from a constitutional or normative perspective. One may look for acceptable allocations of rights according to some ethics criterion. The choice of rights for minorities can, for instance, be realized in a decentralized Wicksellian system based on the equivalence principle, where only (potential) Pareto improvements on some initial situation are to be realized within the community, or the desired allocation of rights may be governed by some other normative principles, such as the maximization of a (paternalistic) welfare function. These principles may or may not consider the effects on other external communities.

In this essay the dynamic impact of assigning rights to certain languages is tied together with the Wicksellian view of an optimal allocation and contrasted with a more welfare-oriented approach. We set up a formal dynamic model of language evolution in section 2 and then specify this model in section 3 in order to analyze first the equivalence-principle approach in section 3.1. Then in section 3.2 it is shown that this approach causes negative externalities outside the ethnic community. Finally, in section 4 , it is demonstrated that in a paternalistic model of justice these externalities have to be relativized.

\subsection{Language and the allocation of rights}

One can distinguish between various characteristics of the goods enjoyed by the individuals in a society. The actual use of a language is an individual matter, giving benefits to the individual using it. ${ }^{1}$ Whether

\footnotetext{
${ }^{1}$ Of course, one person's use of a language might very well affect the well-being of the person it is talking to, or might want to communicate with, producing an externality, be it positive or negative. The larger is the number of speakers of a language, the greater is the potential number of contacts and, hence, the benefit of the language to a person knowing it.
} 
a person chooses to use a certain language or not in a given situation, will to a large extent depend upon the constraints it is facing. One important constraint is, of course, whether one is understood or not and manages to communicate. This can partially be determined by legal rights, forcing, for instance, public offices to accept the use of certain languages in doing official business. Ignoring associated costs, such rights to communication in a certain language can in principle be made available to all individuals to the same extent. Unlike many other rights, like the right to smoke in public places versus the right to enjoy fresh air at the same location, the right to use a certain language in a given setting is a non-exclusive right that does not per se exclude the right to use another language in the same setting: My right to communicate with (and get answers from) a public office in Bislama, say, does not infringe on your right to use Volapük in doing your business with the same office.

Considering the costs of implementing a right, we note that in the dependency on the number of beneficiaries all possible degrees of economies of scale can occur. Having street signs in a certain language, involves only fixed costs, whereas the provision of elementary education is more or less proportional to the number of beneficiaries.

Here we are focusing on these legal rights and not on all the other possibilities to use a language outside the public sector. The latter possibilities are, of course, determined primarily by the number of speakers, but also by other factors, such as the domain in which a certain interaction takes place. In a comprehensive analysis of language rights and justice also these aspects would have to be taken into account. ${ }^{2}$ In this essay, however, we limit the analysis to formal legal rights.

\section{The basic model}

\section{$2.1 \quad$ Notation}

Society at time $t$ is made of a set $N_{t}$ of all individuals born into society at time $t$ as well as the set $N_{t-1}$ of all individuals born at time $t-1$. That is, the set of individuals alive in period $t$ is given by $N_{t} \cup N_{t-1}$. In other words, an individual lives two periods. At birth it is socialized into a certain language $l$, where the set of all languages under consideration is denoted by $L .^{3}$ The number of individuals of cohort $t$ in language group $l$, that is the number of individuals born in period $t$ into group $l$, is written as $n_{t}^{l 0}$. Since individuals live for two periods, the number of older individuals alive at time $t$ is $n_{t-1}^{l 0}$. This is also denoted by $n_{t}^{l 1}$. The total number of individuals in group $l$ at time $t$ is then $n_{t}^{l 0}+n_{t-1}^{l 0}=n_{t}^{l 0}+n_{t}^{l 1}=: n_{t}^{l}$.

Let the set of legally defined domains be $D$. The set of rights in effect at time $t$ is a matrix $r_{t}$ of zeroes and ones. The right to use language $l$ in domain $d$ in period $t$ is then written as $r_{t}^{l d}=1$ and the denial of that right as $r_{t}^{l d}=0$. The propensity of individual $i$ to pay for a certain allocation of rights, $r$, is written as $b^{i}(r)$.

This propensity to pay is, of course, only well defined in relation to a status quo. That is, we normalize the propensities to pay to be equal to zero at the status quo. Two polar choices are $\bar{r}=\mathbb{O}$, all $r^{l d}$ are zero, and $\bar{r}=\mathbb{I}$, all $r^{l d}$ are equal to one. The first case means that our benchmark is that there are no

This network externality is central in the analysis of the long-term dynamics and equilibria of language usage as a means of communication. This is analyzed by, among others, Selten and Pool (1991), Church and King (1993), as well as Güth, Strobel, and Wickström (1997), who look at the benefits of learning other languages in addition to the mother tongue, and Wickström (2005), where the possibilities of the survival of communities of native speakers are analyzed. The present analysis treats this property of language usage as part of the set of the exogenous constraints facing the individual and is, hence, a possible factor influencing its propensity to pay for a certain language right.

${ }^{2}$ For more general analyses in this direction, the reader is referred to, for instance, Kymlicka and Patten (2003) and the references therein. For a more formal analysis, see also Parijs (2002), as well as the contribution of the same author in Kymlicka and Patten (2003).

${ }^{3}$ For the purpose of this essay, we ignore the fact that individuals can belong to several language groups at the same time. The assumption that each individual is associated with one language simplifies the notational problems considerably and does not detract from the principal points of the analysis. 
rights at all in effect and the second signifies that the benchmark is the existence of all possible rights in all domains for all languages.

Intuitively, one can say that, in the first case, we are born without any individual rights, and all rights have to be bought from society. In the second case, we are all born with all possible rights, and the negation of any right has to be bought from the beneficiaries of that right by the rest of society. ${ }^{4}$ For the purpose of this essay, we will assume the former, that is $b^{i}(\mathbb{O})$ is set equal to 0 for all $i$. The right to be able to use a certain language in a certain situation can for our purposes be looked upon as a non-rival good. The "demand" or propensity to pay for this good will vary over the individuals. The sum of all individuals' propensities to pay will then give society's total propensity to pay for this specific right. A difference from the text-book case is that the rights are not continuous, but discrete non-rival goods. Of course, the individual propensity to pay will depend (directly or indirectly) on a number of exogenous factors such as income and prices, but also the availability of other language rights will enter the demand for any specific right to use a certain language. ${ }^{5}$

Let $c(r, n)$ be the costs to society that the realization of the rights allocation $r$ causes. Again, this can only be sensibly defined in relation to the status quo. The costs will depend on a number of factors in addition to $r$. Especially, the number of individuals making use of the right is important. The function $c$ is assumed to be concave in $n^{l}$ if $r^{l d}=1$ for some $d .^{6}$

\subsection{Dynamic structure}

It is reasonable to assume that the rights conveyed on speakers of language $l$ in effect at period $t$ influence the status of that language in that period and, hence, the choice of language of the next generation, that is the size of $n_{t+1}^{l 0} \cdot{ }^{7}$ That is, we assume, that the parents, when they bring up their children, decide on socializing them into their own language or another (majority) language depending on the status of the own language compared to the alternative language(s) - the emotional, cultural aspect - as well as on the number of speakers - the practical, communication aspect. Hence, the distribution of the individuals on the different language groups, as well as the rights given to the speakers of the various languages will determine the size of the groups in the next cohort. That is, the distribution of the next cohort on the language groups is assumed to be given by a function $g$, such that

$$
n_{t+1}^{0}=g\left(r_{t}, n_{t}^{0}\right)
$$

with

$$
\begin{aligned}
& \Delta_{\xi} n_{t+1}^{l 0}:=g^{l}\left(\bar{r}_{t}, n_{t}^{0}\right)-g^{l}\left(\stackrel{\circ}{t}_{t}, n_{t}^{0}\right)>0, \text { if }\left\{\begin{array}{l}
\Delta r_{t}^{m d}:=\bar{r}_{t}^{m d}-\dot{r}_{t}^{m d}=0 \text { for } m \neq l \\
\Delta r_{t}^{l d}=0 \text { for all } d \neq \xi \\
\Delta r_{t}^{l \xi}=1
\end{array}\right. \\
& 1>\frac{\partial g^{l}\left(r_{t}, n_{t}^{0}\right)}{\partial n_{t}^{l 0}} \geq 0,
\end{aligned}
$$

\footnotetext{
${ }^{4}$ For a further discussion of the choice of status quo the reader is referred to Wickström (2007), for instance.

${ }^{5}$ The latter point can be partially operationalized as the "linguistic distance" between the languages. See, for instance, the analysis in Ginsburgh, Ortuño-Ortín, and Weber (2005) or Fidrmuc, Ginsburgh, and Weber (2005). These authors use such a distance as a measure of disenfranchisement. However, the propensity to pay will in general depend on other factors, as well. Especially the emotional attachment to the language seems to be important. Compare, for instance, the situation in Wales, where virtually every Welch-speaker is bilingual in English, too - see, for instance, the statistics in Grin (1992) - or in the Basque country, where almost all speakers of Basque are bilingual in French or Spanish. Nevertheless, the propensity to pay for an official status of the respective language seems to be considerable among its speakers.

${ }^{6}$ For different assumptions on this function, see Wickström (2007).

${ }^{7}$ The long-run effects of certain allocation of language rights would be part of the "emotional" aspect in determining the propensities to pay. The designation of certain languages as "official" in given domains gives them a higher status, which reduces the incentives of following generations to use the non-official ones, reducing the number of their speakers. This can also lead to a situation of diglossia where the domains of the official language are constantly extended at the expense of non-official languages. This, in turn, would give the speakers of the official language a head start in life. In the long run, it might even lead to the death of non-official languages. For a further discussion of this possibility, see Wickström (2005).
} 
where $n_{t}^{0}$ is the vector of all $n_{t}^{l 0}$. The population dynamics is then given by

$$
\dot{n}_{t+1}^{l 0}:=n_{t+1}^{l 0}-n_{t}^{l 0}=g^{l}\left(r_{t}, n_{t}^{0}\right)-n_{t}^{l 0} .
$$

By setting $\dot{n}_{t+1}^{l 0}=0$ for all $l$, we find a (in general) different steady state distribution of the language groups for any given allocation of rights in society:

$$
n^{l 0}(\bar{r})>n^{l 0}(\stackrel{\circ}{r})\left\{\begin{array}{l}
\Delta r^{m d}:=\bar{r}^{m d}-\stackrel{\circ}{ }^{m d}=0 \text { if } m \neq l \\
\Delta r_{t}^{l d} \geq 0 \text { for all } d \\
\Delta r^{l d}=1 \text { for some } d
\end{array} .\right.
$$

This dynamic structure is a crucial assumption of the model.

\section{$2.3 \quad$ Efficiency}

In analyzing the efficient allocation of rights, we look for Pareto efficiency. This can easily be realized applying the compensated-variation criterion.

Let $N$ be the relevant set of individuals and suppress the time index. The aggregated propensity in society, denoted by $b$, to pay for any given allocation of rights, $r$, is then given by

$$
b(r)=\sum_{i \in N} b^{i}(r) .
$$

This would have to be compared to the costs to society of providing these rights. The change in language rights from the status quo, $\bar{r}$, to $r$ is an improvement according to the compensated-variation criterion if

$$
\sum_{i \in N} b^{i}(r)>c(r) .
$$

By introducing compensation payments (or taxes), $\theta^{i}$, we can formulate this slightly differently. The sum of the compensation payments covers the costs of introducing the rights - the introduction is feasible - if $\theta$ is in the set

$$
\Theta^{F}(r):=\left\{\theta \mid \sum_{i \in N} \theta^{i}=c(r)\right\} .
$$

The net benefit to individual $i$ of the allocation of rights $r$ in comparison to the status quo is given by

$$
a^{i}\left(r, \theta^{i}\right):=b^{i}(r)-\theta^{i} .
$$

The necessary requirement that this allocation be a feasible (strong) Pareto improvement, is then that all $a$ be positive, that is, that $\theta$ be in the set defined by

$$
\Theta^{P}(r):=\left\{\theta \in \Theta^{F}(r) \mid a^{i}\left(r, \theta^{i}\right)>0, \forall i\right\} .
$$

A necessary and sufficient condition for the set $\Theta^{P}(r)$ to be non-empty is that the set

$$
\Theta^{E}(r):=\left\{\theta \in \Theta^{F}(r) \mid \sum_{i \in N} a^{i}\left(r, \theta^{i}\right)>0\right\}
$$

be non-empty. Clearly, $\Theta^{P}(r) \subset \Theta^{E}(r)$ and the condition $\Theta^{P}(r) \neq \emptyset$ is equivalent to condition 2.6. If 2.6 holds, we can always find a set of compensation payments such that every individual experiences an improvement on the status quo through the introduction of the allocation of rights $r$. 
The Pareto-efficient allocations can then be found by maximizing the sum of the net benefits, denoted by $S$, over all possible allocations of rights subject to the feasibility constraint 2.7:

$$
\max _{r} S, \text { such that } S:=\sum_{i \in N} a^{i}\left(r, \theta^{i}\right) \text { and } \theta \in \Theta^{F}(r)
$$

This can also be written as

$$
\max _{r}\left[\sum_{i \in N} b^{i}(r)-c(r)\right] .
$$

Denote the set of $r$ solving 2.11 by $\hat{R}$. If $\bar{r} \notin \hat{R}$, then $\Theta^{P}(\hat{r}) \neq \emptyset$, and the efficient allocation can also be realized as a Pareto improvement on the status quo.

\subsection{Rights, fairness and justice}

The liberal theory of justice, also referred to as justice as fairness, basically takes the position that, in making normative judgments, an individual should be able to abstract from its own position in society in order to make decisions about just allocations of resources between all individuals. One should be able to "move oneself into others' shoes". This way of thinking goes back at least as far as antiquity. In Plato $(1888,1980)$ Socrates uses such an argument to justify to Crito why he would not be prepared to leave Athens even in the face of imminent execution. In modern times, Rawls (1971) has become the standard reference in the moral philosophy applied to the social sciences.

Fairness is usually defined as freedom from envy in combination with an efficient allocation of resources. ${ }^{8}$ It is a well-known result, that fair allocations in many situations do not exist. ${ }^{9}$ In other cases, one can also argue that the concept is not very relevant. If we are talking about exclusive rights, for example, any allocation is envy-free, since all individuals have the same right. However, some individuals might value the right more then others. ${ }^{10}$

In the case of non-exclusive rights, like the right to use a language of one's choice, this problem does not arise with the same severity. Also here one could argue that the right to use a certain language in a certain domain is the same for all and hence fair, just as the right to smoke in public places. However, a more reasonable point of departure is also possible. One can, as noted in section 2.4.1 below, choose a status quo where each individual has the same right in relation to a language of its choice and then allow voluntary interchanges in the form of side payments for less rights. This would be in the spirit of fairness. This choice of a status quo with equal rights in this sense, however, is a a priori political issue independent of a strictly wertfrei analysis, and different choices have different implications. ${ }^{11}$

In this essay, we will take as our status quo the absence of all rights and as a first-best optimum define compensation payments in $\Theta^{P}(r)$. A first-best optimum is then realized under the condition that all the externalities to be discussed in section 3 are accounted for.

The problem becomes interesting, however, when certain compensation payments are impossible, restricting the feasible transfers to some politically-institutionally given set $\Psi, \Theta^{P}(r) \cap \Psi=\emptyset$. Here, some kind of trade-off between different individuals has to be defined. Such a definition will always be subjective and political, determined by the preferences of the policy-maker. This trade-off can be formalized with the help of a welfare function.

\footnotetext{
${ }^{8}$ See, for instance, Foley (1967), Varian (1974), or Varian (1975).

${ }^{9}$ Compare, for instance, Varian (1974), Pazner and Schmeidler (1974), or Pazner (1977).

${ }^{10}$ Take as an example the right to smoke or the prohibition on smoking in a public place; both a smoker and a non-smoker enjoy the same right in both instances; hence, in either case, neither of them has any reason to want to exchange their societal position with the other one. Efficiency considerations would tell us in this case which right assignment is the efficient one, but the traditional fairness concept provides us with little guidance as to how to compensate the "loser" in the efficient allocation of rights, that is, telling us what is a "good" allocation of rights (and other goods) in this case.

${ }^{11}$ This is discussed in some detail in Wickström (2007).
} 


\subsubsection{Efficiency versus equality}

In order to address the issue of justice, as already noted, we need some standard of comparison between individuals. We will deal with the individual changes $a^{i}$ from the given status quo and then discuss the criteria for the interpersonal comparison of these changes. The status quo is per definitionem just. This is the basic axiom of our analysis of just distributions. Limiting the analysis to only one sector of society - the allocation of language rights - we are implicitly assuming that injustices in other parts of society are of no consequence for the allocation of language rights.

Contrary to the analysis in section 2.3 it is now assumed that not all transfer payments are possible, but are restricted to some (institutionally given) set $\Psi$ that defines the politically feasible payments. That is, restriction 2.7 is now replaced by

$$
\theta \in \Psi \cap \Theta^{F}(r) .
$$

It is assumed that the vector of zeroes - no transfer payments - is in the set $\Psi$. Then, clearly, $0 \in \Psi \cap \Theta^{F}(r)$ and, by definition, $a^{i}(\bar{r}, 0)=0$.

The welfare function needed to analyze the comparison over individuals, is defined to be a function of the $a$ 's, $W(a)$. Under the assumption that $\Psi \cap \Theta^{F}(r)$ is non-empty the maximization problem then becomes:

$$
\max _{r} W(a) \text { such that } \theta \in \Psi \cap \Theta^{F}(r)
$$

Assuming $W$ to be concave and additively separable in the $a^{i}$, that is

$$
W(a)=\sum_{i \in N} w\left(a^{i}\right),
$$

with $w$ a concave function, the maximization problem can be written as

$$
\max _{r} \sum_{i \in N} \frac{w\left(a^{i}\right)}{a^{i}} a^{i}\left(r, \theta^{i}\right) \text { such that } \theta \in \Psi \cap \Theta^{F}(r)
$$

or

$$
\max _{r} \sum_{i \in N} \beta\left(a^{i}\right) a^{i}\left(r, \theta^{i}\right) \text { such that } \theta \in \Psi \cap \Theta^{F}(r) .
$$

By not making $w$, and, hence, $\beta$, dependent on $i$, we assume that all individuals are treated symmetrically. The function $\beta\left(a^{i}\right)$ is the policy variable of the planner determining the degree of inequality aversion, giving different weights to the individuals according to their net gains. If the planner is not concerned about distributional issues, all $\beta\left(a^{i}\right)$ are constant and identical, $\beta\left(a^{i}\right)=\beta$, and the maximization problem searches the efficient allocation:

$$
\max _{r} \beta \sum_{i \in N} a^{i}\left(r, \theta^{i}\right) \text { such that } \theta \in \Psi \cap \Theta^{F}(r)
$$

This is equivalent to:

$$
\max _{r}\left[\sum_{i \in N} b^{i}(r)-c(r)\right]
$$

If all weight is given to the person with the lowest gain (or largest loss), the case of extremely egalitarian policy, we have:

$$
\max _{r} \min _{i \in N}\left\{a^{i}\left(r, \theta^{i}\right)\right\} \text { such that } \theta \in \Psi \cap \Theta^{F}(r)
$$

The planner will minimize the loss of the biggest loser. In general, there is a trade-off between efficiency and equality and the choice of the function $\beta(a)$ determines the amount of trade-off that is deemed (politically) acceptable. 


\section{The efficient allocation of language rights}

We will illustrate the analytical framework above with the aid of a simple example. In spite of its simplicity, the example suffices for our purposes in this essay which is to address the dynamic issue of rights allocation. We limit ourselves to two languages and two language groups, $A$ and $B$. An individual $i$ belongs to either group. Group $A$ is the majority and $B$ the minority, and we analyze the efficiency of providing full rights to the minority language in any of the domains $D$, denoted by $r^{B d}=1$, if the right is granted, and $r^{B d}=0$, if it is not. Assuming "selfish" preferences, we let the propensity to pay for such a right for language $B$ be $b^{i}=0$, if $i \in N^{A}$, and $b^{i}>0$, if $i \in N^{B}$. Further, let $b^{i}$ be additive in the various rights:

$$
b^{i}\left(r^{B}\right)=\sum_{d} b^{i}\left(r^{B d}\right)
$$

Let the size of the two groups be $n^{A}$ and $n^{B}$, respectively, and the cost of providing the right, $c\left(r^{B d}, n^{B}\right)$. The function $c$ is assumed to be concave in $n^{B} \cdot{ }^{12}$ Let

$$
b^{i B d}:=\left.b^{i}\left(r^{B d}\right)\right|_{r^{B d}=1}
$$

and

$$
c^{B d}\left(n^{B}\right):=\left.c\left(r^{B d}, n^{B}\right)\right|_{r^{B d}=1} .
$$

It will now, in a static setting, be efficient to provide the right in domain $d$ if

$$
S^{B d}:=\sum_{i \in N^{B}} b^{i B d}-c^{B d}\left(n^{B}\right) \geq 0 .
$$

We can rewrite this condition as

$$
n^{B} b^{B d}-c^{B d}\left(n^{B}\right) \geq 0
$$

or

$$
b^{B d}-\frac{c^{B d}\left(n^{B}\right)}{n^{B}} \geq 0,
$$

where $b^{B d}$ is the average propensity of the $B$ individuals to pay for the right.

We can now order the domains according to the size of $S^{B d}$ with the highest value for $d=1$ and successively lower (or same) value for increasing values of $d$. There will then be a critical value $d^{*}$ such that, for all $d \leq d^{*}, S^{B d} \geq 0$ and, for all $d>d^{*}, S^{B d}<0$. That is, it is efficient to introduce rights for language $B$ in domains $1,2, \ldots, d^{*}$ and not in domains $d^{*}+1, d^{*}+2, \ldots, D .{ }^{13}$

Since an individual is alive for two periods and the generations overlap, the problem is slightly more complex, however. In period $t$ there will be both young and old individuals in the two groups. The size of the different groups is $n_{t}^{A 0}$ and $n_{t}^{A 1}\left(=n_{t-1}^{A 0}\right)$ as well as $n_{t}^{B 0}$ and $n_{t}^{B 1}\left(=n_{t-1}^{B 0}\right)$, respectively. Further, $n_{t}^{l}:=n_{t}^{l 0}+n_{t}^{l 1}$. Correspondingly, we denote the propensities to pay for individuals alive in period $t$ by $b_{t}^{i 0}$ and $b_{t}^{i 1}$. Furthermore, the average propensities are defined as

$$
\begin{aligned}
b_{t}^{l 0} & :=\frac{1}{n_{t}^{l 0}} \sum_{i \in N_{t}^{l 0}} b_{t}^{i 0} \\
b_{t}^{l 1} & :=\frac{1}{n_{t}^{l 1}} \sum_{i \in N_{t}^{l 1}} b_{t}^{i 1} \\
b_{t}^{l} & :=\frac{1}{n_{t}^{l}}\left(\sum_{i \in N_{t}^{l 1}} b_{t}^{i 1}+\sum_{i \in N_{t}^{l 0}} b_{t}^{i 0}\right) .
\end{aligned}
$$

\footnotetext{
${ }^{12}$ For different assumptions on this function, see Wickström (2007).

${ }^{13}$ We are implicitly assuming that there is at least one domain, in which it is inefficient to introduce the right. Else, our problem becomes trivial.
} 
The total discounted aggregated net propensity to pay for realizing the right in domain $d$ at time $t=0$ can be decomposed into three effects. There is the one obvious direct effect and two indirect effects due to the fact that the future $n^{B}$ changes and that the future $r^{B}$ also might change as a consequence. The effect on the cost-benefit calculation of the introduction of the right in domain $d$ at time $t$ now becomes: ${ }^{14}$

$$
\begin{aligned}
& \Delta_{d} S^{B}=n_{0}^{B 1} b_{0}^{B d 1}+n_{0}^{B 0} b_{0}^{B d 0}-c^{B d}\left(n_{0}^{B 1}+n_{0}^{B 0}\right) \\
& +\sum_{\xi} \sum_{t=1}^{\infty}\left[n_{t}^{B 1} b_{t}^{B \xi 1}+n_{t}^{B 0} b_{t}^{B \xi 0}-c^{B \xi}\left(n_{t}^{B 1}+n_{t}^{B 0}\right)\right] \delta^{t} \Delta_{d} r_{t}^{B \xi} \\
& +\sum_{\xi} \sum_{t=1}^{\infty}\left[\left(b_{t}^{B \xi}-\frac{c^{B \xi}\left(n_{t}^{B}\right)}{n_{t}^{B}}\right)-n_{t}^{B} \frac{\partial}{\partial n_{t}^{B}}\left(\frac{c^{B \xi}\left(n_{t}^{B}\right)}{n_{t}^{B}}\right)\right] \delta^{t} r_{t}^{B \xi} \Delta_{d} n_{t}^{B} \\
& =S_{0}^{B d}+\sum_{t=1}^{\infty} \delta^{t} \sum_{\xi}\left\{S_{t}^{B \xi} \Delta_{d} r_{t}^{B \xi}+\left[\frac{S_{t}^{B \xi}}{n_{t}^{B}}-n_{t}^{B} \frac{\partial}{\partial n_{t}^{B}}\left(\frac{c^{B \xi}\left(n_{t}^{B}\right)}{n_{t}^{B}}\right)\right] r_{t}^{B \xi} \Delta_{d} n_{t}^{B}\right\}
\end{aligned}
$$

where $\delta \leq 1$ is a discount factor and the dynamics of $n^{B}$ is given by

$$
\dot{n}_{t+1}^{B 0}:=n_{t+1}^{B 0}-n_{t}^{B 0}=g\left(r_{t}^{B}, n_{t}^{B 0}\right)-n_{t}^{B 0}=: h\left(r_{t}^{B}, n_{t}^{B 0}\right) .
$$

The analysis of the problem of finding an optimal allocation of rights, that is finding a sequence of $r_{t}^{B}$ that is efficient, can be divided into several cases. We can see it from the point of view of all - present and future $-B$ individuals or from the point of view of only the $B$ individuals alive in period $t$. We can also consider the effect on the $A$ individuals, that is possible external effects due to the introduction of rights for language $B$.

\subsection{Group-internal considerations}

If only the interests of the group are taken into consideration, there are two basic views to consider. Either only the individuals alive at a certain time are to be counted in the decisions. This can be seen as close to a constitutional-economics analysis and is in the tradition of the equivalence principle. It is not unreasonable to assume that individuals will seek institutional set-ups leading to efficient allocations. This is the question asked in constitutional economics and it has its roots in the work of Wicksell. A more normative point of view takes also unborn generations into account. We will see that the results then can differ from the more egocentric view.

\subsubsection{Cohort-centered analysis}

The total aggregated propensity to pay for the right for language $B$ in domain $d$ at time $t$ and $t+1$ of the individuals living at time $t$, that is the gross benefit to the individuals alive at time $t$ of the right being in effect in periods $t$ and $t+1$, is now

$$
\sum_{i \in N^{B_{t}}} b_{t}^{i 1}+\sum_{i \in N^{B_{t}}} b_{t}^{i 0}+\delta \sum_{i \in N^{B_{t}}} b_{t+1}^{i 1}=n_{t}^{B 1} b_{t}^{B 1}+n_{t}^{B 0} b_{t}^{B 0}+\delta n_{t+1}^{B 1} b_{t+1}^{B 1}=n_{t}^{B} b_{t}^{B}+\delta n_{t+1}^{B 1} b_{t+1}^{B 1} .
$$

The cost of providing the right at time $t$ is $c^{B d}\left(n_{t}^{B 1}+n_{t}^{B 0}\right)=c^{B d}\left(n_{t}^{B}\right)$ and at time $t+1, c^{B d}\left(n_{t+1}^{B}\right)$; from the latter costs, however, in order to get the compensated variation, the propensities to pay of the next generation alive in period $t+1$ have to be subtracted. From the point of view of the individuals

\footnotetext{
${ }^{14}$ Because of the discrete changes in $n_{t+1}^{B}$, this, of course, is a first-order approximation of the effect. However, higher-order effects cannot change the qualitative conclusions.
} 
living in period $t$, the cost-benefit calculation of the introduction of the right in domain $d$, equation 3.8, hence, becomes

$$
\Delta_{d} S_{t}^{B}=S_{t}^{B d}+\delta \sum_{\xi}\left\{S_{t+1}^{B \xi} \Delta_{d} r_{t+1}^{B \xi}+\left[\frac{S_{t+1}^{B \xi}}{n_{t+1}^{B}}-n_{t+1}^{B} \frac{\partial}{\partial n_{t+1}^{B}}\left(\frac{c^{B \xi}\left(n_{t+1}^{B}\right)}{n_{t+1}^{B}}\right)\right] r_{t+1}^{B \xi} \Delta_{d} n_{t+1}^{B}\right\} .
$$

In comparison to the static case, we have a second and third term due to the increase in $n_{t+1}^{B}$ because of the increased status of language $B$ caused by granting it the right in domain $d$ in period $t$. We need to find a set of domains

$$
\hat{D}_{t}=\left\{d \in D \mid \Delta_{d} S_{t}^{B} \geq 0\right\} .
$$

We note that $\hat{D}$ is not necessarily unique, since $\Delta_{d} n_{t+1}^{B}$ is a function of the whole vector $r_{t+1}^{B}$ (not only of $\left.r_{t+1}^{B d}\right)$. We can also define the set of domains for which the static criterion is satisfied:

$$
D_{t}^{*}=\left\{d \in D \mid S_{t}^{B d} \geq 0\right\}
$$

That is, using the static criterion, we have that $d \in D_{t}^{*}$ is equivalent to setting $r_{t \xi}^{B d}=1$. Due to the concavity of $c$, we see that $n_{t+1}^{B}>n_{t}^{B}$ implies that $D_{t}^{*} \subset D_{t+1}^{*}$ and, hence, $\Delta_{d} r_{t+1}^{B \xi} \geq 0$ for all $\xi$. Since the term after the minus sign in the square brackets of the third term of 3.11 is negative due to the concavity of $c$ in $n$, the application of the static criterion to expression 3.11 implies that $\Delta_{d} S_{t}^{B} \geq 0$ and that $D_{t}^{*} \subset \hat{D}_{t}$. It is readily seen that it in general is a proper subset, since for small values of $\xi$ the second and third terms will be strictly positive, allowing the first term to become negative without violating the dynamic criterion.

We can then conclude that the static criterion for introducing language rights is too restrictive, and, due to the dynamic structure of the problem, minority rights should go further than a simple static analysis indicates.

\subsubsection{Intergenerational efficiency}

The net future benefits are given by expression 3.8. In comparison to the analysis in section 3.1, we see that the correction due to the intertemporal structure has increased, since the change in the number of individuals in the $B$ group not only increases in the period after the introduction of the right, but, of course, continues to be bigger than in the alternative scenario - no right in period $t$-due to the dynamic structure defined in expression 2.2 .

\subsubsection{Steady state}

We can also compare the steady states of intergenerational efficiency with and without a certain right in effect. To simplify things, we consider the situation with and without a right $d$. All rights in the sets $\{1, \ldots, d-1\}$ and $\{d+1, \ldots, D\}$ are assumed to be unaffected by the decision on $d$. Further, let $n^{B}(0)$ be the steady-state size of the $B$ community without right $d$ in effect and correspondingly $n^{B}(1)$ if right $d$ is in effect. The criterion for keeping right $d$ if it has been in effect is then $\Delta_{d} S^{B}(1) \geq 0$ with

$$
\begin{aligned}
& \Delta_{d} S^{B}(1)=n^{B}(1)\left(b^{B d}-\frac{c^{B d}\left(n^{B}(1)\right)}{n^{B}(1)}\right) \\
& +\sum_{\xi=1}^{d}\left[\left(b^{B \xi}-\frac{c^{B \xi}\left(n^{B}(1)\right)}{n^{B}(1)}\right)-n^{B}(1) \frac{\partial}{\partial n^{B}}\left(\frac{c^{B \xi}\left(n^{B}(1)\right)}{n^{B}(1)}\right)\right] \sum_{t=1}^{\infty} \delta^{t} \Delta_{d} n^{B}(1)
\end{aligned}
$$


and the criterion for not introducing right $d$ if it has not been in effect is $\Delta_{d} S^{B}(0)<0$ with

$$
\begin{aligned}
& \Delta_{d} S^{B}(0)=n^{B}(0)\left(b^{B d}-\frac{c^{B d}\left(n^{B}(0)\right)}{n^{B}(0)}\right) \\
& +\sum_{\xi=1}^{d}\left[\left(b^{B \xi}-\frac{c^{B \xi}\left(n^{B}(0)\right)}{n^{B}(0)}\right)-n^{B}(0) \frac{\partial}{\partial n^{B}}\left(\frac{c^{B \xi}\left(n^{B}(0)\right)}{n^{B}(0)}\right)\right] \sum_{t=1}^{\infty} \delta^{t} \Delta_{d} n^{B}(0) .
\end{aligned}
$$

Since $\Delta_{d} n^{B}(1)$ and $\Delta_{d} n^{B}(0)$ could be assumed to be arbitrarily small and $n^{B}(1)>n^{B}(0)$, it is clear that the situation

$$
\Delta_{d} S^{B}(1)>0>\Delta_{d} S^{B}(0)
$$

is not unreasonable, making both allocations of rights efficient in the long run. In other words, the problem of finding an intergenerationally efficient allocation of rights is path-dependent. The analysis of the case of the cohort-centered analysis is, of course, totally parallel.

\subsubsection{Discussion}

The simple analysis in this section has demonstrated that the naive static criterion for determining the compensated variation of the introduction of language rights tends to underestimate the net benefits of the rights to the speech community. What our analysis tells us, is that a static analysis of the net benefits will lead to a too small set of realized rights, since the status effect on the language of the introduction of the right would not be sufficiently accounted for. In nuce, it is efficient from the point of view of a language community to introduce rights that go beyond the instantaneous cost-benefit calculations.

\subsection{Global considerations}

In addition to the effects analyzed above, there is also an effect on the $A$ group. If a right is introduced in period $t$ and, as a consequence, the $B$ group increases by $\Delta_{d} n_{t+1}^{B}$ in the subsequent period, then, by constant cohort size, the size of the next $A$ generation, $n_{t+1}^{A}$, will decrease by $\Delta_{d} n_{t+1}^{B}$ and the aggregated propensity to pay for the right of language $A$ in the next generation will also decrease. In the cost-benefit calculus in the cohort-centered analysis, the young individuals in period $t$ will hence suffer a loss in period $t+1$, giving us a total aggregated change to the $A$ individuals alive in period $t$ equal to

$$
\begin{aligned}
& \Delta_{d} S_{t}^{A}=-\delta \sum_{\xi}\left[b_{t+1}^{A \xi}-\frac{\partial c^{A \xi}\left(n_{t+1}^{A}\right)}{\partial n_{t+1}^{A}}\right] \Delta_{d} n_{t+1}^{B} \\
& =-\delta \sum_{\xi}\left[\frac{S_{t+1}^{A \xi}}{n_{t+1}^{A}}-n_{t+1}^{A} \frac{\partial}{\partial n_{t+1}^{A}}\left(\frac{c^{A \xi}\left(n_{t+1}^{A}\right)}{n_{t+1}^{A}}\right)\right] \Delta_{d} n_{t+1}^{B}<0 .
\end{aligned}
$$

This loss would in a global analysis have to be compared to the gain to the $B$ community, found in expression 3.11:

$$
\Delta_{d} S_{t}^{B}=S_{t}^{B d}+\delta \sum_{\xi}\left\{S_{t+1}^{B \xi} \Delta_{d} r_{t+1}^{B \xi}+\left[\frac{S_{t+1}^{B \xi}}{n_{t+1}^{B}}-n_{t+1}^{B} \frac{\partial}{\partial n_{t+1}^{B}}\left(\frac{c^{B \xi}\left(n_{t+1}^{B}\right)}{n_{t+1}^{B}}\right)\right] r_{t+1}^{B \xi} \Delta_{d} n_{t+1}^{B}\right\}
$$

and the total gain to society would be

$$
\Delta_{d} S_{t}=\Delta_{d} S_{t}^{A}+\Delta_{d} S_{t}^{B}
$$

Since ex hypothesi $n_{t+1}^{B}<n_{t+1}^{A}$ and $c$ is concave in $n$ the change to the $A$ community is negative, and the consideration of the externality implies a reduction in the number of rights put in effect in the $B$ 
community. Indeed, $\Delta_{d} S_{t}^{A}$ is bigger in absolute value than the third term of $\Delta_{d} S_{t}^{B}$ and, since more rights are in effect for the $A$ group, it can be considerably so. Hence, the use of the static criterion does not imply that $\Delta_{d} S_{t}>0$. That is, what is efficient according to the static criterion, is not necessarily efficient if the externality is taken into account. We, hence, would have to reverse the conclusions in the previous section. It can be efficient to introduce less minority rights than what a simple static analysis would imply. We can find an "efficient discrimination" of minorities.

\section{Welfare-optimal allocations of rights}

Returning to the problem in section 3.2, we now modify the efficiency analysis and introduce the welfare function from section 2.4.1. Firstly, we look at the problem when the costs of the rights are carried by the respective communities. Within the community everyone pays the same tax. Then, we analyze the situation when the costs are equally divided among all individuals in both communities.

\subsection{Intracommunity cost-sharing}

Here, the set $\Psi$, defining the political restrictions, is given by

$$
\Psi=\left\{\theta \mid \theta^{i}=\theta^{j}=\sum_{d} \frac{c^{l d}\left(n_{t}^{l}\right)}{n_{t}^{l}}, \forall i, j \in N^{l}, l \in\{A, B\}\right\} .
$$

The $a$ 's are

$$
a_{t}^{A i}=\sum_{d}\left(b_{t}^{A d i}-\frac{c^{A d}\left(n_{t}^{A}\right)}{n_{t}^{A}}\right)
$$

and

$$
a_{t}^{B i}=\sum_{d}\left(b_{t}^{B d i}-\frac{c^{B d}\left(n_{t}^{B}\right)}{n_{t}^{A}}\right) r_{t}^{B d}
$$

respectively. The welfare function from section 2.17 now becomes:

$$
\begin{aligned}
& W=\sum_{t=0}^{\infty} \delta^{t} \sum_{i \in N} \beta\left(a^{i}\right) a^{i}\left(r, \theta^{i}\right) \\
= & \sum_{t=0}^{\infty} \delta^{t}\left[\sum_{i \in N^{A}} \beta\left(a_{t}^{A i}\right) \sum_{d}\left(b_{t}^{A d i}-\frac{c^{A d}\left(n_{t}^{A}\right)}{n_{t}^{A}}\right)+\sum_{i \in N^{B}} \beta\left(a_{t}^{B i}\right) \sum_{d}\left(b_{t}^{B d i}-\frac{c^{B d}\left(n_{t}^{B}\right)}{n_{t}^{A}}\right) r_{t}^{B d}\right] \\
= & \sum_{t=0}^{\infty} \delta^{t}\left[\beta_{t}^{A} \sum_{d} n_{t}^{A}\left(b_{t}^{A d}-\frac{c^{A d}\left(n_{t}^{A}\right)}{n_{t}^{A}}+\frac{V^{A d}}{\beta_{t}^{A}}\right)+\beta_{t}^{B} \sum_{d} n_{t}^{B}\left(b_{t}^{B d}-\frac{c^{B d}\left(n_{t}^{B}\right)}{n_{t}^{B}}+\frac{V^{B d}}{\beta_{t}^{B}}\right) r_{t}^{B d}\right] \\
= & \sum_{t=0}^{\infty} \delta^{t}\left[\beta_{t}^{A} S_{t}^{A}+\beta_{t}^{B} S_{t}^{B}+\sum_{d}\left(n_{t}^{A} V^{A d}+n_{t}^{B} V^{B d} r_{t}^{B d}\right)\right]
\end{aligned}
$$

Here, $\beta_{t}^{l}$ is defined by

$$
\beta_{t}^{l}:=\frac{1}{n^{l}} \sum_{i \in N^{l}} \beta\left(a_{t}^{l i}\right)
$$

and $V^{l d}$ is a measure of the heterogeneity of the $l$ community defined by:

$$
V^{l d}:=\frac{\sum_{i \in N^{l}}\left(\beta_{t}^{l i}-\beta_{t}^{l}\right)\left(b_{t}^{l d i}-b_{t}^{l d}\right)}{n_{t}^{l}}
$$


If the planner wants to redistribute in favor of the losers, the $\beta$ 's will be negatively correlated with the $b$ 's and $V^{l d}$ will be negative.

The introduction of the right for speakers of language $B$ in domain $d$ at time $t \geq 0$ will affect the welfare in various ways: ${ }^{15}$

$$
\Delta_{d} W=\sum_{t=0}^{\infty} \delta^{t}\left[\beta_{t}^{A} \Delta_{d} S_{t}^{A}+\beta_{t}^{B} \Delta_{d} S_{t}^{B}+n_{t}^{B} V^{B d}+\sum_{\xi}\left(V^{B \xi} r_{t}^{B \xi}-V^{A \xi}\right) \Delta_{d} n_{t}^{B}\right]
$$

We first have the direct effect on the $B$ community, $\Delta_{d} S_{t}^{B}$, and the externality on the $A$ community, $\Delta_{d} S_{t}^{A}$, due to the change in $n_{t}^{B}$ from time $t=1$. This is the same phenomenon as analyzed in section 3.2 above. ${ }^{16}$ Given that $n^{A}>n^{B}$ and that rights are realized in all domains for the members of the $B$ community, we readily see that for any two individuals $i \in N^{A}$ and $j \in N^{B}$, if $b_{t}^{A d i}=b_{t}^{B d j}$ for all domains $d$, then $a_{t}^{A i}>a_{t}^{B j}$, since due to concavity

$$
\frac{c^{A d}\left(n_{t}^{A}\right)}{n_{t}^{A}}<\frac{c^{B d}\left(n_{t}^{B}\right)}{n_{t}^{B}} .
$$

A planner, wanting to redistribute in favor of the weaker individuals, will, hence, give higher weight to individual $i$ than to individual $j$. If the distributions of the propensities to pay $b$ are similarly distributed among the individuals in the two communities, then as a consequence $\beta_{t}^{B}>\beta_{t}^{A}$ and the negative externality on the $A$ community will have a lower weight than in the corresponding efficiency problem in section 3.2. This signifies that the term $\Delta_{d} S_{t}^{B}$ can take on lower values than in the efficiency case without making the change in welfare negative. That is, rights in more domains become acceptable in the paternalistic welfare analysis.

However, we have a negative effect due to the dispersion measure $V$. Since the planner wants to redistribute in favor of the losers, more weight will be given to the individuals with low values of $b$ the consideration of the right becoming effective in the new domain, which will tend to reduce the change in welfare and, hence, the likelihood of introducing the right.

Finally, there is the intertemporal effect of the introduction of the right causing an increase in $n^{B}$. This will not only affect the costs, which is already taken into account in $\Delta_{d} S_{t}^{A}$ and $\Delta_{d} S_{t}^{B}$, but also the heterogeneity measures within the two communities, negatively due to $V^{B \xi}$ and positively due to $V^{A \xi}$. We note that if the two communities are homogenous, that is, if $b_{t}^{A d i}=\beta_{t}^{A d}$ and $b_{t}^{B d i}=\beta_{t}^{B d}$ for all $i$ and $d$, then $V^{A \xi}$ and $V^{B \xi}$ are all equal to zero and the result is clear: By giving more weight to the relative losers, it is desirable to give more rights to the minority language, than what comes out of a pure efficiency analysis.

\subsection{Universal cost-sharing}

We now assume that the costs of the rights must be distributed equally among all individuals, that is:

$$
\Psi=\left\{\theta \mid \theta^{i}=\theta^{j}, \forall i, j \in N\right\}
$$

The $a$ 's are then

$$
a_{t}^{A i}=\sum_{d}\left[b_{t}^{A d i}-\left(\frac{c^{A d}\left(n_{t}^{A}\right)}{n_{t}^{A}+n_{t}^{B}}+\frac{c^{B d}\left(n_{t}^{B}\right)}{n_{t}^{A}+n_{t}^{B}} r_{t}^{B d}\right)\right]
$$

\footnotetext{
${ }^{15}$ We are implicitly assuming that the changes in the weights $\beta$ and the dispersion measure $V$ due to the introduction of a new (marginal) right are negligible.

${ }^{16}$ The difference is only that we are now looking at the effect on all future generations, whereas in section 3.2 we limited the analysis to the individuals alive at time $t=0$. The present analysis could easily be limited to the cohort-centered case, which would have no consequence for the qualitative results.
} 
for an $A$ individual and

$$
a_{t}^{B i}=\sum_{d}\left[b_{t}^{B d i} r_{t}^{B d}-\left(\frac{c^{A d}\left(n_{t}^{A}\right)}{n_{t}^{A}+n_{t}^{B}}+\frac{c^{B d}\left(n_{t}^{B}\right)}{n_{t}^{A}+n_{t}^{B}} r_{t}^{B d}\right)\right]
$$

for a $B$ individual. The welfare criterion from equation 2.17 then becomes:

$$
\begin{aligned}
& W=\sum_{t=0}^{\infty} \delta^{t} \sum_{i \in N} \beta\left(a^{i}\right) a^{i}\left(r, \theta^{i}\right) \\
= & \sum_{t=0}^{\infty} \delta^{t} \sum_{d}\left\{\sum_{i \in N^{A}} \beta\left(a_{t}^{A i}\right)\left[b_{t}^{A d i}-\left(\frac{c^{A d}\left(n_{t}^{A}\right)}{n_{t}^{A}+n_{t}^{B}}+\frac{c^{B d}\left(n_{t}^{B}\right)}{n_{t}^{A}+n_{t}^{B}} r_{t}^{B d}\right)\right]\right. \\
& \left.+\sum_{i \in N^{B}} \beta\left(a_{t}^{B i}\right)\left[b_{t}^{B d i} r_{t}^{B d}-\left(\frac{c^{A d}\left(n_{t}^{A}\right)}{n_{t}^{A}+n_{t}^{B}}+\frac{c^{B d}\left(n_{t}^{B}\right)}{n_{t}^{A}+n_{t}^{B}} r_{t}^{B d}\right)\right]\right\} \\
= & \sum_{t=0}^{\infty} \delta^{t} \sum_{d}\left\{\beta_{t}^{A} S_{t}^{A d}+\beta_{t}^{B} S_{t}^{B d} r_{t}^{B d}+n_{t}^{A} V^{A d}+n_{t}^{B} V^{B d} r_{t}^{B d}\right. \\
& \left.+\left(\beta_{t}^{B}-\beta_{t}^{A}\right)\left[\frac{n_{t}^{A}}{n_{t}} c^{B d}\left(n_{t}^{B}\right) r_{t}^{B d}-\frac{n_{t}^{B}}{n_{t}} c^{A d}\left(n_{t}^{A}\right)\right]\right\}
\end{aligned}
$$

Here,

$$
n_{t}:=n_{t}^{A}+n_{t}^{B}
$$

We see that the welfare measure consists of several components, the well-being of the $A$ community, weighted by $\beta^{A}$, the well-being of the $B$ community, weighted by $\beta^{B}$, and a fiscal externality, weighted by $\left(\beta_{t}^{B}-\beta_{t}^{A}\right)$. We will look at the fiscal externality in more detail in the following.

If all $\beta$ are identical, the fiscal externality disappears and the $V$ become equal to zero. The expression reduces to

$$
W=\beta \sum_{t=0}^{\infty} \delta^{t} \sum_{d}\left(S_{t}^{A d}+S_{t}^{B d} r_{t}^{B d}\right)=\beta S
$$

which brings us back to the efficiency criterion. If both communities are homogeneous, the expression becomes:

$$
W=\sum_{t=0}^{\infty} \delta^{t} \sum_{d}\left\{\beta_{t}^{A} S_{t}^{A d}+\beta_{t}^{B} S_{t}^{B d} r_{t}^{B d}+\left(\beta_{t}^{B}-\beta_{t}^{A}\right)\left[\frac{n_{t}^{A}}{n_{t}} c^{B d}\left(n_{t}^{B}\right) r_{t}^{B d}-\frac{n_{t}^{B}}{n_{t}} c^{A d}\left(n_{t}^{A}\right)\right]\right\}
$$

The introduction of a marginal right in domain $d$ at time $t \geq 0$ then causes a change in welfare equal to:

$$
\begin{aligned}
& \Delta_{d} W=\sum_{t=0}^{\infty} \delta^{t}\left\{\beta_{t}^{A} \Delta_{d} S_{t}^{A}+\beta_{t}^{B} \Delta_{d} S_{t}^{B}+\left(\beta^{B}-\beta^{A}\right) \sum_{\xi} \Delta_{d}\left[\frac{n_{t}^{A}}{n_{t}} c^{B \xi}\left(n_{t}^{B}\right) r_{t}^{B \xi}-\frac{n_{t}^{B}}{n_{t}} c^{A \xi}\left(n_{t}^{A}\right)\right]\right\} \\
& =\sum_{t=0}^{\infty} \delta^{t}\left\{\beta_{t}^{A} \Delta_{d} S_{t}^{A}+\beta_{t}^{B} \Delta_{d} S_{t}^{B}+\left(\beta_{t}^{B}-\beta_{t}^{A}\right) \frac{n_{t}^{A}}{n_{t}} c^{B d}\left(n_{t}^{B}\right)\right. \\
& +\left(\beta_{t}^{B}-\beta_{t}^{A}\right) \sum_{\xi}\left[\left(\eta^{B \xi}\left(1-\frac{n_{t}^{B}}{n}\right)-\frac{n_{t}^{B}}{n}\right) \frac{c^{B \xi}\left(n_{t}^{B}\right)}{n_{t}^{B}} r_{t}^{B \xi}\right. \\
& \left.\left.+\left(\eta^{A \xi}\left(1-\frac{n_{t}^{A}}{n}\right)-\frac{n_{t}^{A}}{n}\right) \frac{c^{A \xi}\left(n_{t}^{A}\right)}{n_{t}^{A}}\right] \Delta_{d} n_{t}^{B}\right\}
\end{aligned}
$$


Here the elasticities $\eta$ are defined by

$$
\eta_{t}^{l \xi}:=\frac{\frac{\partial c^{l \xi}\left(n_{t}^{l}\right)}{\partial n_{t}^{l}}}{\frac{c^{l \xi}\left(n_{t}^{l}\right)}{n_{t}^{l}}} .
$$

We have assumed that no other right is changed as a consequence of the introduction of the right in domain $d: \Delta_{d} r_{t}^{B \xi}=0$ for $\xi \neq d$. Again, the change in welfare is determined by three effects, a direct externality on the $A$ community, which is negative with weight $\beta^{A}$, a direct effect on the $B$ community, with weight $\beta^{B}$, as well as several fiscal externalities. Hence, in addition to the case in section 4.1 we have the fiscal externalities. The first one is the obvious direct one; the $A$ community contributes to the financing of the implementation of the right in domain $d$ in the $B$ community; an advantage for the $B$ community and a clear disadvantage for the $A$ community.

The second fiscal externality depends on the dynamic structure and has two components. Firstly, because of the increase in the size of the $B$ community and the corresponding decrease in the size of the $A$ community, a larger share of the public budget falls on the $B$ community compared to the efficiency case in section 3.2. Secondly, the costs of implementing all rights decrease in the $A$ community, but increase per capita due to the convexity of the cost functions. Similarly, the implementation costs of the rights in the $B$ community increase, but decrease per capita. Of course these fiscal externalities work in opposite directions in the two communities, which is reflected in the signs of the weights. The net effect is unclear and depends on the elasticities of the cost functions. If only fixed costs are encountered, the elasticities are zero and the effect is a negative one for the $B$ community. If the cost functions are linear, the elasticities are equal to one, and the effect is a positive one for the $B$ community, since, by assumption, $n_{t}^{B} / n<1 / 2$.

Intuitively, in first case the costs in the $A$ community do not change, but the number of individuals decreases, and some of the costs are therefore shifted to the $B$ community which increases in size. In the second case both the number of individuals and the costs in the $A$ community decrease proportionally and correspondingly increase proportionally in the $B$ community. Since the $A$ community is bigger than the $B$ group, the relief in the tax share of the $B$ people due to the reduction in the costs of the implemented rights in the $A$ community is greater than the increase due to the increase in the size of the $B$ community. The contribution from the $A$ community to the financing of the rights in the $B$ community will then, by the corresponding argument, increase, since the size of the $A$ community is greater than that of the $B$ group.

In comparison to the analysis in section 4.1 we see that the direct fiscal externality adds a further argument in favor of more rights for the minority, whereas the indirect fiscal externality via the dynamic effect in some cases relativizes this effect.

\section{Concluding remarks}

In this essay we have tried to examine systematically the factors influencing the normative arguments for the allocation of language rights to a linguistic minority from an economic point of view. We have seen that a simple static cost-benefit analysis has to be augmented in various directions. If there are dynamic implications of the rights assignment, strengthening the minority numerically, this brings an argument in favor of more rights for the minority. However, such a dynamic effect creates a negative externality for the majority, which more than compensates for the positive effect on the minority, delivering an argument for an optimal discrimination of the minority. If we leave the simple cost-benefit paradigm and introduce a redistributive policy in favor of the losers in society, these conclusions again have to be modified and there are arguments for giving less weight to the externality on the majority due to the dynamic structure. These positive effects on the minority are further strengthened in the presence of a fiscal externality on the minority, which will be compensated through more rights than in the previous case. 
The scope of the study has been limited to rights in formal domains which can be regulated by legal means. The larger - and probably more important - issue of how to deal with linguistic discrimination in the market place, has been totally ignored. Also the question what constitutes a legitimate minority, is not the topic of this essay. Should recent immigrants be treated differently from minorities, whose ancestors have lived in a territory for numerous generations, often much longer than the majority population? A related question is: When does a newly arrived group become the legitimate majority in a territory and left-over members of the old majority a "normal" minority? This opens up many interesting, contradictory and important questions, which can be approached and partially resolved by economic methodology. These are, however, the topics left for future essays.

\section{References}

Church, Jeffrey and IAn King (1993). "Bilingualism and network externalities". In: Canadian Journal of Economics/Revue canadienne d'économique 26, pages 337-345.

Fidrmuc, Jan, Victor Ginsburgh, and Shlomo Weber (2005). Economic challenges of multilingual societies. Research report.

Foley, Duncan (1967). "Resource allocation in the public sector". In: Yale Economic Essays 7, pages $73-76$.

Ginsburgh, Victor, Ignacio Ortuño-Ortín, and Shlomo Weber (2005). "Disenfranchisement in linguistically diverse societies. The case of the European Union". In: Journal of the European Economic Association 3, pages 946-965.

GRIN, FRANÇOIS (1992). "Towards a threshold theory of minority language survival". In: Kyklos $4 \mathbf{4 5}$ pages $69-97$.

Güth, Werner, Martin Strobel, and Bengt-Arne Wickström (1997). "Equilibrium selection in linguistic games: Kial ni (ne) parolas esperanton?" In: Understanding strategic interaction: Essays in honor of Reinhard Selten. Edited by Wulf Albers, Werner Güth, Peter Hammerstein, Benny Moldovanu, and ERIC VAn Damme. Berlin: Springer, pages 257-269.

Kymlicka, Will and Alan Patten, editors (2003). Language rights and political theory. Oxford: Oxford University Press.

PariJs, Philippe VAn (2002). "Linguistic justice". In: Politics, Philosophy and Economics 1.1, pages $59-74$.

PAzner, Elisha A. (1977). "Pitfalls in the theory of fairness". In: Journal of Economic Theory 14, pages $458-466$.

Pazner, Elisha A. and David Schmeidler (1974). "A difficulty in the theory of fairness". In: Review of Economic Studies 41, pages 441-443.

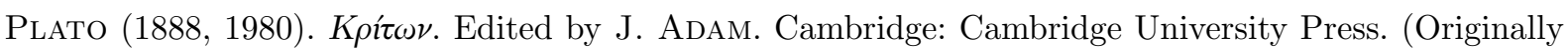

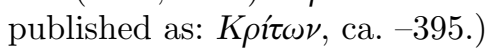

Rawls, John (1971). A theory of justice. Cambridge: Harvard University Press.

Selten, Reinhard and Jonathan Pool (1991). "The distribution of foreign language skills as a game equilibrium". In: Game equilibrium models IV. Edited by REINHARD SELTEN. Berlin: Springer, pages $64-84$.

VArian, Hal R. (1974). "Equity, envy, and efficiency". In: Journal of Economic Theory 9, pages 63-91. 
VARIAn, Hal R. (1975). "Distributive justice, welfare economics and the theory of fairness". In: Philosophy and Public Affairs 4, pages 223-247.

WiCKStröm, Bengt-Arne (2005). "Can bilingualism be dynamically stable? A simple model of language choice". In: Rationality and Society 17.1, pages 81-115.

- (2007). "Fairness, rights, and language rights: On the fair treatment of linguistic minorities". In: Public Economics and Public Choice. Edited by Pio BaAke and Rainald Borck. Berlin: Springer, pages $81-101$. 


\section{CESifo Working Paper Series}

for full list see www.cesifo-group.org/wp

(address: Poschingerstr. 5, 81679 Munich, Germany, office@cesifo.de)

2893 Johannes Binswanger and Daniel Schunk, What is an Adequate Standard of Living during Retirement?, December 2009

2894 Armin Falk and James J. Heckman, Lab Experiments are a Major Source of Knowledge in the Social Sciences, December 2009

2895 Hartmut Egger and Daniel Etzel, The Impact of Trade on Employment, Welfare, and Income Distribution in Unionized General Oligopolistic Equilibrium, December 2009

2896 Julian Rauchdobler, Rupert Sausgruber and Jean-Robert Tyran, Voting on Thresholds for Public Goods: Experimental Evidence, December 2009

2897 Michael McBride and Stergios Skaperdas, Conflict, Settlement, and the Shadow of the Future, December 2009

2898 Ben J. Heijdra and Laurie S. M. Reijnders, Economic Growth and Longevity Risk with Adverse Selection, December 2009

2899 Johannes Becker, Taxation of Foreign Profits with Heterogeneous Multinational Firms, December 2009

2900 Douglas Gale and Piero Gottardi, Illiquidity and Under-Valuation of Firms, December 2009

2901 Donatella Gatti, Christophe Rault and Anne-Gaël Vaubourg, Unemployment and Finance: How do Financial and Labour Market Factors Interact?, December 2009

2902 Arno Riedl, Behavioral and Experimental Economics Can Inform Public Policy: Some Thoughts, December 2009

2903 Wilhelm K. Kohler and Marcel Smolka, Global Sourcing Decisions and Firm Productivity: Evidence from Spain, December 2009

2904 Marcel Gérard and Fernando M. M. Ruiz, Corporate Taxation and the Impact of Governance, Political and Economic Factors, December 2009

2905 Mikael Priks, The Effect of Surveillance Cameras on Crime: Evidence from the Stockholm Subway, December 2009

2906 Xavier Vives, Asset Auctions, Information, and Liquidity, January 2010

2907 Edwin van der Werf, Unilateral Climate Policy, Asymmetric Backstop Adoption, and Carbon Leakage in a Two-Region Hotelling Model, January 2010 
2908 Margarita Katsimi and Vassilis Sarantides, Do Elections Affect the Composition of Fiscal Policy?, January 2010

2909 Rolf Golombek, Mads Greaker and Michael Hoel, Climate Policy without Commitment, January 2010

2910 Sascha O. Becker and Ludger Woessmann, The Effect of Protestantism on Education before the Industrialization: Evidence from 1816 Prussia, January 2010

2911 Michael Berlemann, Marco Oestmann and Marcel Thum, Demographic Change and Bank Profitability. Empirical Evidence from German Savings Banks, January 2010

2912 Øystein Foros, Hans Jarle Kind and Greg Shaffer, Mergers and Partial Ownership, January 2010

2913 Sean Holly, M. Hashem Pesaran and Takashi Yamagata, Spatial and Temporal Diffusion of House Prices in the UK, January 2010

2914 Christian Keuschnigg and Evelyn Ribi, Profit Taxation and Finance Constraints, January 2010

2915 Hendrik Vrijburg and Ruud A. de Mooij, Enhanced Cooperation in an Asymmetric Model of Tax Competition, January 2010

2916 Volker Meier and Martin Werding, Ageing and the Welfare State: Securing Sustainability, January 2010

2917 Thushyanthan Baskaran and Zohal Hessami, Globalization, Redistribution, and the Composition of Public Education Expenditures, January 2010

2918 Angel de la Fuente, Testing, not Modelling, the Impact of Cohesion Support: A Theoretical Framework and some Preliminary Results for the Spanish Regions, January 2010

2919 Bruno S. Frey and Paolo Pamini, World Heritage: Where Are We? An Empirical Analysis, January 2010

2920 Susanne Ek and Bertil Holmlund, Family Job Search, Wage Bargaining, and Optimal Unemployment Insurance, January 2010

2921 Mariagiovanna Baccara, Allan Collard-Wexler, Leonardo Felli and Leeat Yariv, Gender and Racial Biases: Evidence from Child Adoption, January 2010

2922 Kurt R. Brekke, Roberto Cellini, Luigi Siciliani and Odd Rune Straume, Competition and Quality in Regulated Markets with Sluggish Demand, January 2010

2923 Stefan Bauernschuster, Oliver Falck and Niels Große, Can Competition Spoil Reciprocity? - A Laboratory Experiment, January 2010 
2924 Jerome L. Stein, A Critique of the Literature on the US Financial Debt Crisis, January 2010

2925 Erkki Koskela and Jan König, Profit Sharing, Wage Formation and Flexible Outsourcing under Labor Market Imperfection, January 2010

2926 Gabriella Legrenzi and Costas Milas, Spend-and-Tax Adjustments and the Sustainability of the Government’s Intertemporal Budget Constraint, January 2010

2927 Piero Gottardi, Jean Marc Tallon and Paolo Ghirardato, Flexible Contracts, January 2010

2928 Gebhard Kirchgässner and Jürgen Wolters, The Role of Monetary Aggregates in the Policy Analysis of the Swiss National Bank, January 2010

2929 J. Trent Alexander, Michael Davern and Betsey Stevenson, Inaccurate Age and Sex Data in the Census PUMS Files: Evidence and Implications, January 2010

2930 Stefan Krasa and Mattias K. Polborn, Competition between Specialized Candidates, January 2010

2931 Yin-Wong Cheung and Xingwang Qian, Capital Flight: China’s Experience, January 2010

2932 Thomas Hemmelgarn and Gaetan Nicodeme, The 2008 Financial Crisis and Taxation Policy, January 2010

2933 Marco Faravelli, Oliver Kirchkamp and Helmut Rainer, Social Welfare versus Inequality Concerns in an Incomplete Contract Experiment, January 2010

2934 Mohamed El Hedi Arouri and Christophe Rault, Oil Prices and Stock Markets: What Drives what in the Gulf Corporation Council Countries?, January 2010

2935 Wolfgang Lechthaler, Christian Merkl and Dennis J. Snower, Monetary Persistence and the Labor Market: A New Perspective, January 2010

2936 Klaus Abberger and Wolfgang Nierhaus, Markov-Switching and the Ifo Business Climate: The Ifo Business Cycle Traffic Lights, January 2010

2937 Mark Armstrong and Steffen Huck, Behavioral Economics as Applied to Firms: A Primer, February 2010

2938 Guglielmo Maria Caporale and Alessandro Girardi, Price Formation on the EuroMTS Platform, February 2010

2939 Hans Gersbach, Democratic Provision of Divisible Public Goods, February 2010

2940 Adam Isen and Betsey Stevenson, Women’s Education and Family Behavior: Trends in Marriage, Divorce and Fertility, February 2010 
2941 Peter Debaere, Holger Görg and Horst Raff, Greasing the Wheels of International Commerce: How Services Facilitate Firms’ International Sourcing, February 2010

2942 Emanuele Forlani, Competition in the Service Sector and the Performances of Manufacturing Firms: Does Liberalization Matter?, February 2010

2943 James M. Malcomson, Do Managers with Limited Liability Take More Risky Decisions? An Information Acquisition Model, February 2010

2944 Florian Englmaier and Steve Leider, Gift Exchange in the Lab - It is not (only) how much you give ..., February 2010

2945 Andrea Bassanini and Giorgio Brunello, Barriers to Entry, Deregulation and Workplace Training: A Theoretical Model with Evidence from Europe, February 2010

2946 Jan-Emmanuel De Neve, James H. Fowler and Bruno S. Frey, Genes, Economics, and Happiness, February 2010

2947 Camille Cornand and Frank Heinemann, Measuring Agents' Reaction to Private and Public Information in Games with Strategic Complementarities, February 2010

2948 Roel Beetsma and Massimo Giuliodori, Discretionary Fiscal Policy: Review and Estimates for the EU, February 2010

2949 Agnieszka Markiewicz, Monetary Policy, Model Uncertainty and Exchange Rate Volatility, February 2010

2950 Hans Dewachter and Leonardo Iania, An Extended Macro-Finance Model with Financial Factors, February 2010

2951 Helmuth Cremer, Philippe De Donder and Pierre Pestieau, Education and Social Mobility, February 2010

2952 Zuzana Brixiová and Balázs Égert, Modeling Institutions, Start-Ups and Productivity during Transition, February 2010

2953 Roland Strausz, The Political Economy of Regulatory Risk, February 2010

2954 Sanjay Jain, Sumon Majumdar and Sharun W. Mukand, Workers without Borders? Culture, Migration and the Political Limits to Globalization, February 2010

2955 Andreas Irmen, Steady-State Growth and the Elasticity of Substitution, February 2010

2956 Bengt-Arne Wickström, The Optimal Babel - An Economic Framework for the Analysis of Dynamic Language Rights, February 2010 